\title{
Diazepam, Given Postischemia, Protects Selectively Vulnerable Neurons in the Rat Hippocampus and Striatum
}

\author{
Rochelle D. Schwartz, Xiao Yu, Melanie R. Katzman, Diane M. Hayden-Hixson, and Jean M. Perry \\ Department of Pharmacology, Duke University Medical Center, Durham, North Carolina 27710
}

Following cerebral ischemia, certain populations of neurons degenerate. Excessive accumulation of excitatory amino acids in the synaptic cleft, activation of excitatory amino acid receptors, and influx of calcium into neurons play a key role in the development of ischemia-induced neuronal death. We hypothesized that neuroprotection may be achieved by enhancing inhibitory (i.e., $\gamma$-aminobutyric acid, GABA) neurotransmission to offset excitation. Dlazepam, a drug that increases GABA-induced chloride channel opening, was administered (10 $\mathrm{mg} / \mathrm{kg}$, i.p.) to rats 1 and $2 \mathrm{hr}$ following 15 min of transient global ischemia, when hippocampal GABA levels, increased during ischemia, returned to basal. Rats were maintained normothermic during ischemia and became hypothermic following the injections of diazepam. Four days later, rats were sacrificed and the brains were examined for neuronal degeneration and the presence of GABA $_{A}$ receptors labeled by ${ }^{35} \mathrm{~S}$-t-butylbicyclophosphorothionate $\left({ }^{35} \mathrm{~S}\right.$ TBPS). There was substantial neuroprotection of striatal neurons and pyramidal neurons in the CA1 area of the hippocampus. In addition, diazepam prevented the loss of ${ }^{35} \mathrm{~S}-$ TBPS binding sites in the striatum and in the dendritic fields of the CA1 hippocampus following ischemia. Since hypothermia, itself, is neuroprotective, we determined if hypothermia was required for the ability of diazepam to produce neuroprotection. Diazepam was microinjected into the CA1 hippocampus 1 and $2 \mathrm{hr}$ following ischemia, and rats remained normothermic. Four days later, diazepam still produced substantial protection of hippocampal neurons. Thus, postischemic hypothermia may have contributed to the neuroprotection by diazepam when it was administered systemically, but the neuroprotective effect of diazepam did not require hypothermia. We conclude that delayed enhancement of GABAergic neurotransmission directly at the site of vulnerability following an ischemic event protects the vulnerable neurons from death.

[Key words: cerebral ischemia, neuronal death, $\mathbf{G A B A}_{\mathrm{A}}$ receptor, diazepam, neuroprotection, hypothermia]

\footnotetext{
Received Apr. 5, 1994; revised June 8, 1994; accepted July 19, 1994.

We gratefully acknowledge Dr. Helene Benveniste for her generous help setting up the 4 vessel occlusion technique and in vivo microdialysis and Dr. Huiling Li for her help with the histological scoring. This work was supported by NIH Grant NS28791 to R.D.S., NIH Training grant ES07031 to D.H.H., and the Howard Hughes Undergraduate Research Forum to M.R.K. R.D.S. is an Established Investigator of the American Heart Association.

Correspondence should be addressed to Rochelle D. Schwartz, Department of Pharmacology, Box 3813, Duke University Medical Center, Durham, NC 27710. Copyright (c) 1995 Society for Neuroscience $0270-6474 / 95 / 150529-11 \$ 05.00 / 0$
}

Transient cerebral ischemia is produced when the brain is deprived temporarily of oxygen and glucose. After cardiac arrest with resuscitation or cardiopulmonary bypass surgery, cerebral ischemia can lead to problems with cognition and memory, to serious neurological problems such as sensorimotor deficits and seizures, and to death (Levy et al., 1985; Volpe and Petito, 1985; Newburger et al., 1993). In humans and in animals subjected to transient cerebral ischemia, specific neurons degenerate following the ischemic episode (Ito et al., 1975; Kirino, 1982; Pulsinelli et al., 1982; Petito et al., 1987). The striatum, hippocampus, and somatosensory cortex are particularly sensitive. In animal models, neurons in the striatum and somatosensory cortex degenerate quickly after the onset of reperfusion (within $1 \mathrm{~d}$ ), while pyramidal neurons in the CA1 sector of the hippocampus degenerate 3-4 d later ("delayed neuronal death") (Kirino, 1982; Pulsinelli et al., 1982; Crain et al., 1988). The delayed degeneration of neurons provides the opportunity for neuroprotective agents to be administered following the ischemic insult.

There have been numerous studies in animals to assess neuroprotective efficacy of various classes of drugs following transient global (cerebral) and focal ischemia, although there is no satisfactory treatment for humans. Most of these studies have focused on glutamate receptor antagonists because excessive activation of glutamate receptors by excitatory amino acid neurotransmitters released during ischemia and the subsequent rise in intracellular calcium are important triggers in the development of ischemia-induced neuronal death (Rothman, 1984; Benveniste et al., 1984; Choi, 1988; Schurr and Rigor, 1992). Neuroprotective efficacy (limited to complete) has been demonstrated not only by glutamate receptor antagonists (Simon et al., 1984; Gill et al., 1988; Sheardown et al., 1990; Nellgard and Wieloch, 1992; Li and Buchan, 1993), but also by drugs affecting several other neurotransmitter systems, by calcium channel antagonists, and by lipid peroxidation inhibitors (for review, Krieglstein, 1990; Schurr and Rigor, 1992).

We have been interested in the role of inhibitory neurotransmission in ischemia-induced neuronal death. Inhibitory neurotransmission [mediated principally by $\gamma$-aminobutyric acid (GABA)] normally provides a balance for cxcitatory ncurotransmission (mediated principally by glutamate) in many areas of the brain. Thus, pharmacological enhancement of GABA neurotransmission is an alternative therapeutic strategy to the use of excitatory amino acid antagonists for neuroprotection following an ischemic event. The benzodiazepines, which have anxiolytic, sedative/hypnotic, anticonvulsant, and muscle relaxant properties, are the most commonly used drugs to enhance $\mathrm{GABA}_{\mathrm{A}}$ neurotransmission (Tallman et al., 1980; Rall, 1990). 


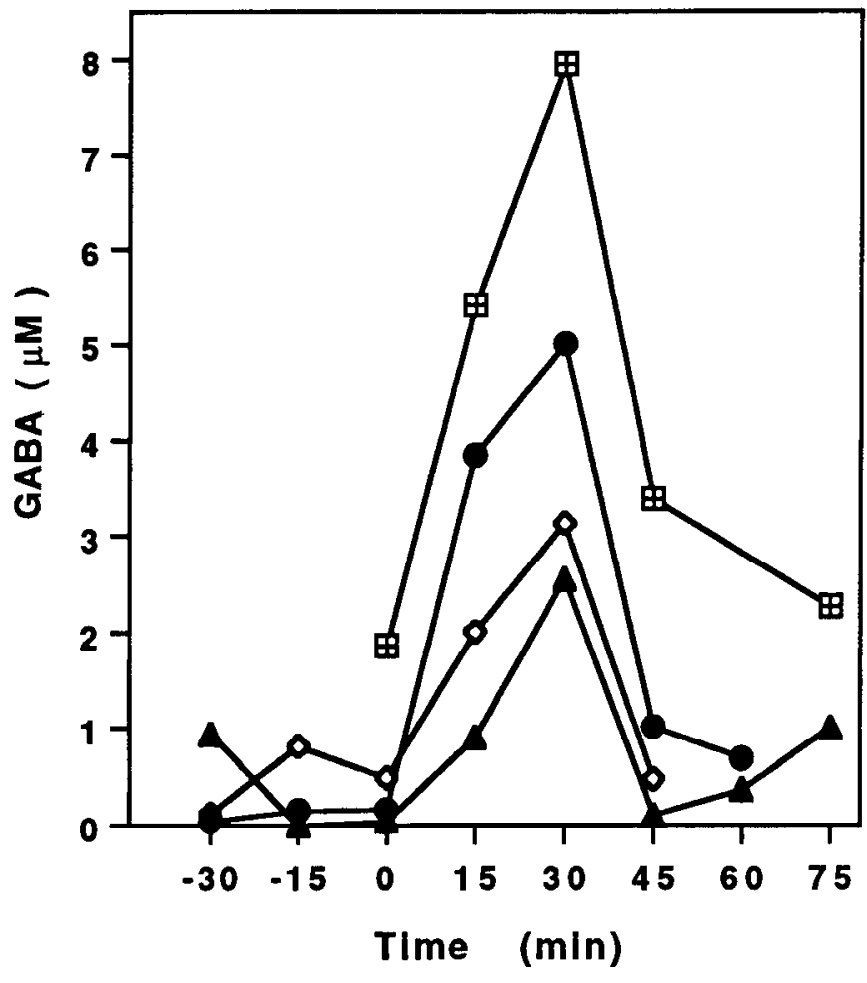

Figure 1. Ischemia induces accumulation of GABA in the CAI area of the hippocampus. Extracellular GABA concentrations in the CA1 hippocampus were measured using in vivo microdialysis before, during, and after transient global ischemia as described in Materials and Methods. Ischemia was initiated at time 0 . Each curve is from an individual rat. Values are GABA $(\mu \mathrm{M})$ in the dialysate.

Benzodiazepines, such as diazepam, bind to a site associated with the $\mathrm{GABA}_{\mathrm{A}}$ receptor to increase the frequency of opening of the GABA-gated chloride channel (Study and Barker, 1981; Rall, 1990). Benzodiazepines and other drugs that enhance GABA neurotransmission (e.g., GABA agonists and uptake and metabolism inhibitors) produce varying degrees of ncuroprotection when administered before or during cerebral ischemia in rodents (Sternau et al., 1989; Kato et al., 1990; Johansen and Diemer, 1991; Shuaib et al., 1992; Shuaib et al., 1993). Based on these studies, GABA-enhancing drugs should be efficacious when used before and during surgical procedures which limit blood flow to the brain. Given immediately after cerebral ischemia in gerbils, benzodiazepines have failed to produce neuroprotection (Sternau et al., 1989). However, there may be a "therapeutic window" after an ischemic event has already occurred, during which a drug can be administered and produce neuroprotection. Therefore, we have determined if the delayed administration of the benzodiazepine, diazepam, following transient global ischemia is neuroprotective in selectively vulnerable regions of the rat striatum and hippocampus. In addition, we have determined if neuroprotection by diazepam results from enhancement of GABA neurotransmission directly at the site of vulnerability.

These results have been presented in preliminary form ( $\mathrm{Yu}$ et al., 1993) and support our recent study using a gerbil model of transient forebrain ischemia (Schwartz et al., 1994a).

\section{Materials and Methods}

Surgical procedures. Adult male Wistar rats (300-350 gm) were subjected to the 4 vessel occlusion technique, as described previously by
Benveniste et al. (1984), with modifications. The vertebral arteries of rats were electrocauterized (under halothane anesthesia) and the following day the carotid arteries were occluded for $15 \mathrm{~min}$. Rats were anesthetized with $2.5 \%$ halothane in breathing air, and the tail artery was cannulated so that blood pressure could be monitored and blood could be withdrawn as necessary. Subdermal cortical EEG leads were placed over the cerebral cortex for the monitoring of EEG, and temperature probes were placed in the temporalis muscle and rectum. After rats were stabilized, the carotid arteries were isolated and occluded with silk sutures for $15 \mathrm{~min}$. Blood pressure was reduced to approximately $60 \mathrm{~mm}$ $\mathrm{Hg}$ by withdrawal of blood through the tail artery cannula. Both temporalis muscle and rectal temperatures were monitored throughout the procedure, and maintained between 36 and $37^{\circ} \mathrm{C}$ using a heating pad and an incandescent lamp placed over the head. EEG activity became isoelectric within seconds of the occlusion and the halothane anesthesia was discontinued. After 15 min, reflow was established by release of the sutures and verified visually. Any blood withdrawn was returned to the rat via the tail artery. Sham-operated rats received identical treatment, except the carotid arteries were not occluded. Rats recovered after surgery in separate cages.

In a separate experiment, rats were implanted with guide cannulas 1 week prior to microinjections into the CAl sector of the hippocampus on both sides of the brain. The same time course for dosing was used as for the systemic dosing regimen. Sixty and 120 minutes following ischemia, diazepam (50 $\mathrm{ng}$ or $1.25 \mu \mathrm{g}$ ) was microinjected directly into the CAl sector of the hippocampus at the rate of $0.2 \mu \mathrm{l} / \mathrm{min}$ over a 2.5 min period. The injection cannula was positioned so that it did not pierce the hippocampus; the tip was aimed at the alveus. The coordinates for injection were: $3.3 \mathrm{~mm}$ posterior to bregma, $2.2 \mathrm{~mm}$ lateral to bregma, angled $10^{\circ}$ from vertical, and $2.42 \mathrm{~mm}$ below the surface of the skull. The contralateral hippocampus was injected with vehicle $(20 \%$ polycthylene glycol in artificial cerebrospinal fluid). Rats were maintained normothermic during the ischemia, and rectal temperature was measured for $3 \mathrm{hr}$ following the ischemia and injections of diazepam.

In vivo microdialysis. A separate group of rats was used for in vivo microdialysis recordings. Two hours prior to the occlusion of the carotid arteries, a microdialysis probe (CMA-12, $1 \mathrm{~mm}$ tip; Bio Analytical Systems, West Lafayette, IN) was implanted stereotactically into the CA1 area of the right dorsal hippocampus. The coordinates were; 3.6 $\mathrm{mm}$ posterior to bregma, $2.0 \mathrm{~mm}$ lateral to bregma, and $3.5 \mathrm{~mm}$ below the skull surface. The hippocampus was perfused with artificial cerebrospinal fluid consisting of $122 \mathrm{mM} \mathrm{NaCl}, 3 \mathrm{mM} \mathrm{KCl}, 1.2 \mathrm{mM} \mathrm{CaCl}_{2}$, $1.2 \mathrm{mM} \mathrm{MgSO}_{4}, 0.4 \mathrm{mM} \mathrm{KH}_{2} \mathrm{PO}_{4}$, and $25 \mathrm{mM} \mathrm{NaHCO}$, pH 7.35, at a rate of $2 \mu \mathrm{l} / \mathrm{min}$. Occlusion of the carotid arteries commenced after 2 $\mathrm{hr}$ of perfusion to obtain a stable baseline. Perfusates $(30 \mu \mathrm{l})$ were collected cvery $15 \mathrm{~min}$ and stored at $20^{\circ} \mathrm{C}$ until assaycd for amino acid concentrations by HPLC.

Measurement of extracellular GABA. GABA and other amino acids, including glutamate, were measured in the dialysates after derivatization with $o$-phthaldialdehyde (OPA) by HPLC with dual detection, as previously reported, with modifications (Schwartz et al., 1994b). Dialysates $(30 \mu \mathrm{l})$ were mixed with homoserine as the internal standard and incubated with OPA and $\beta$-mercaptoethanol for $2.5 \mathrm{~min}$ at $6^{\circ} \mathrm{C}$. Twenty microliters of the reaction mixture was injected onto an ESA HR-80 C 18 column $(3 \mu \mathrm{m})$. The mobile phase was isocratic and contained 0.1 M sodium phosphate dibasic buffer in $25 \%$ methanol $(\mathrm{pH}=6.75)$. The flow rate was $1.2 \mathrm{ml} / \mathrm{min}$. For the electrochemical detector, the guard cell potential was set at $650 \mathrm{mV}$, and the analytical cell potentials were set at -400 and $+600 \mathrm{mV}$. The fluorescence detector was set to an excitation wavelength of $330 \mathrm{~nm}$, and the emission filter was $418 \mathrm{~nm}$. Chromatograms were analyzed on an LDC LCTalk workstation (Riviera Beach, $F L$ ), which calculated the ratio of sample peak area to the internal standard peak area. The sensitivity for GABA detection was 50 fmol (with 2:1 signal to noise).

Drug injections. Ischemic and sham-operated rats were injected i.p. with either $10 \mathrm{mg} / \mathrm{kg}$ diazepam or vehicle $(33 \%$ polyethylene glycol in saline) $60 \mathrm{~min}$ and again $120 \mathrm{~min}$ following the onset of ischemia. Rectal temperature was monitored for several hours to assess the degree of hypothermia induced by diazepam. Microinjections of diazepam into the hippocampus are described under Surgical procedures.

Histological assessment of neuronal degeneration. Four days following onset of reperfusion, rats were decapitated, and the brains were removed, frozen in isopentane, and stored at $-70^{\circ} \mathrm{C}$. Frozen brains were cut into $20 \mu \mathrm{m}$ sections at the level of the striatum and the dorsal hippocampus. Adjacent sections were mounted on subbed glass slides for histological 


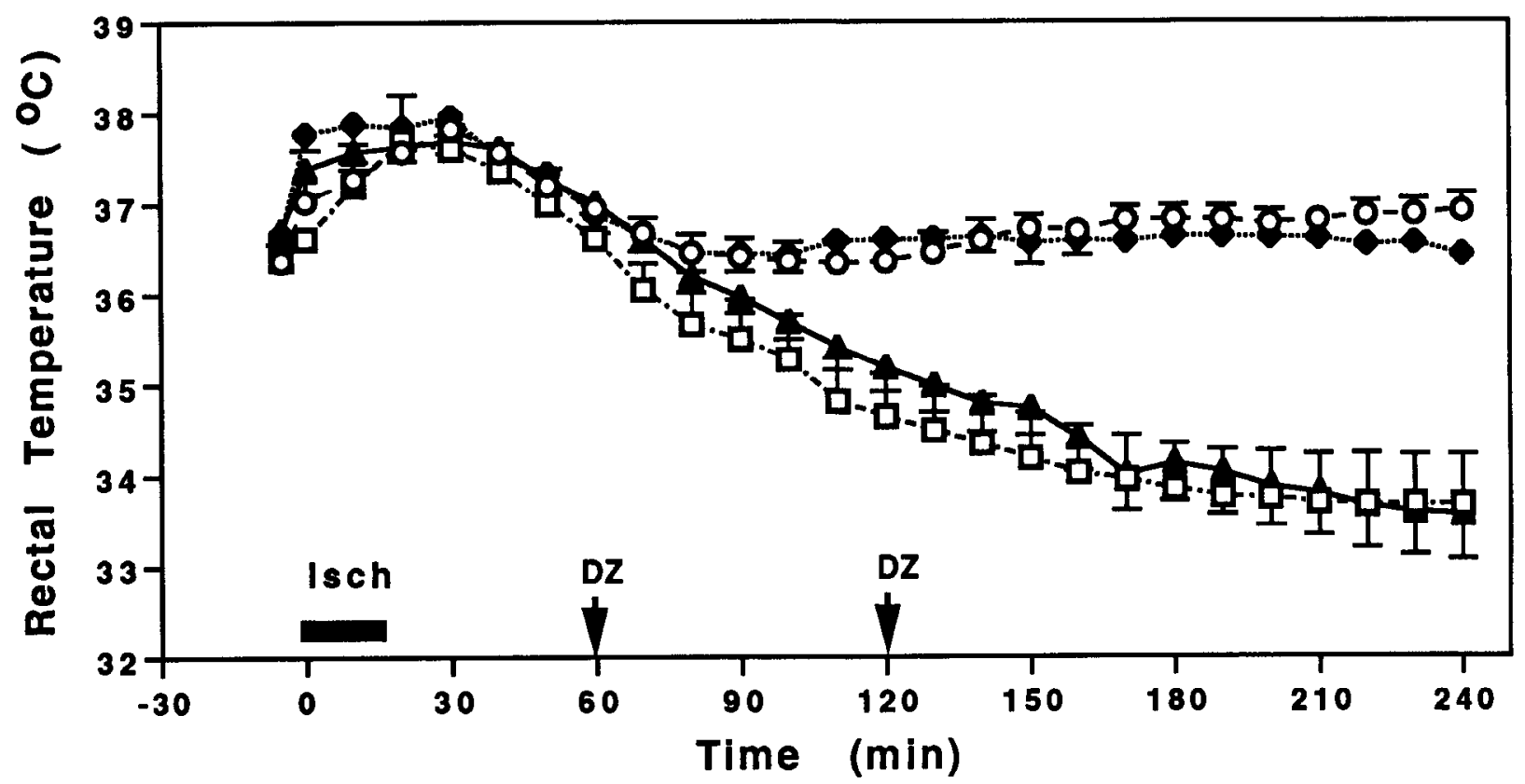

Figure 2. Diazepam produces hypothermia following cerebral ischemia. Rectal temperatures were measured in rats subjected to global cerebral ischemia for $15 \mathrm{~min}$ and administered vehicle or diazepam $(D Z)(10 \mathrm{mg} / \mathrm{kg}$, i.p.) 60 and $120 \mathrm{~min}$ following ischemia. Data are the mean $\pm \mathrm{SEM}$ for 6-7 rats. $O$, sham; ischemia; $\square$, sham $+D Z ; \square$, ischemia $+D Z$.

analysis and ${ }^{35} \mathrm{~S}$-t-butylbicyclophosphorothionate ( $\left.{ }^{35} \mathrm{~S}-\mathrm{TBPS}\right)$ autoradiography (see below). Slices were stained with thionin and viable cells were visualized using a light microscopc. To quantitate damage to the striatum, the area of damage was digitized using Image 1.49 image analysis software and compared to the total striatal area to give the percent of area damaged. In the hippocampus, the extent of damage was measured in $1 \mathrm{~mm}$ segments of the CAla, CA1b, and CAlc areas of dorsal hippocampus using a variation of the rating scale described by Pulsinelli et al. (1982). Histological examination of bilateral hippocampi was made by two blinded observers using the following rating scale: $0-<25 \%$ cells lost, $1-25-50 \%$ cells lost, $2-50-75 \%$ cells lost, and $3->75 \%$ cells lost.

In a separate experiment, when diazepam was microinjected into the hippocampus, rats were sacrificed $4 \mathrm{~d}$ after the ischemia by transcardial perfusion with saline then paraformaldehyde (4\%). The perfused brains were sliced into $40 \mu \mathrm{m}$ sections using a freezing microtome and subjected

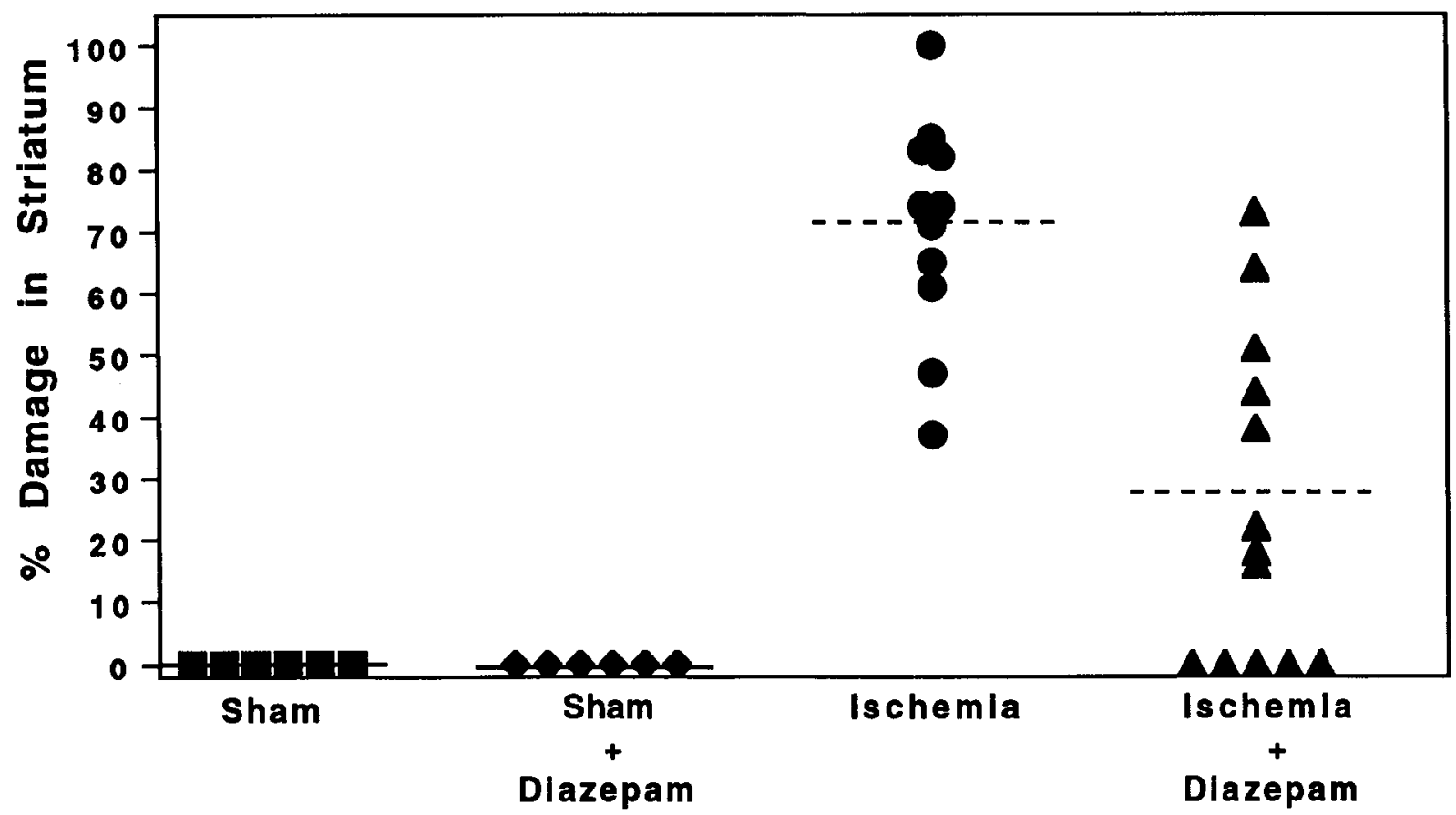

Figure 3. Diazepam protects striatal neurons and spares $\mathrm{GABA}_{\mathrm{A}}$ receptors in dorsolateral striatum following cerebral ischemia. Rats were sacrificed $4 \mathrm{~d}$ following transient global ischemia, and thionin-stained sections of striatum were examined for degeneration as described in Materials and Methods. Rats were administered diazepam $(10 \mathrm{mg} / \mathrm{kg}) 60$ and $120 \mathrm{~min}$ after cerebral ischemia. Each symbol is from an individual rat. The horizontal lines represent the mean value for each group. There was significant protection of striatal neurons by diazepam. $p=0.0005, \mathrm{Kruskal}-$ Wallis test followed by the Mann-Whitney $U$ test $(n=6,6,11$, and 13 , respectively). 


\section{Thionin}

\section{${ }^{35}$ S-TBPS}

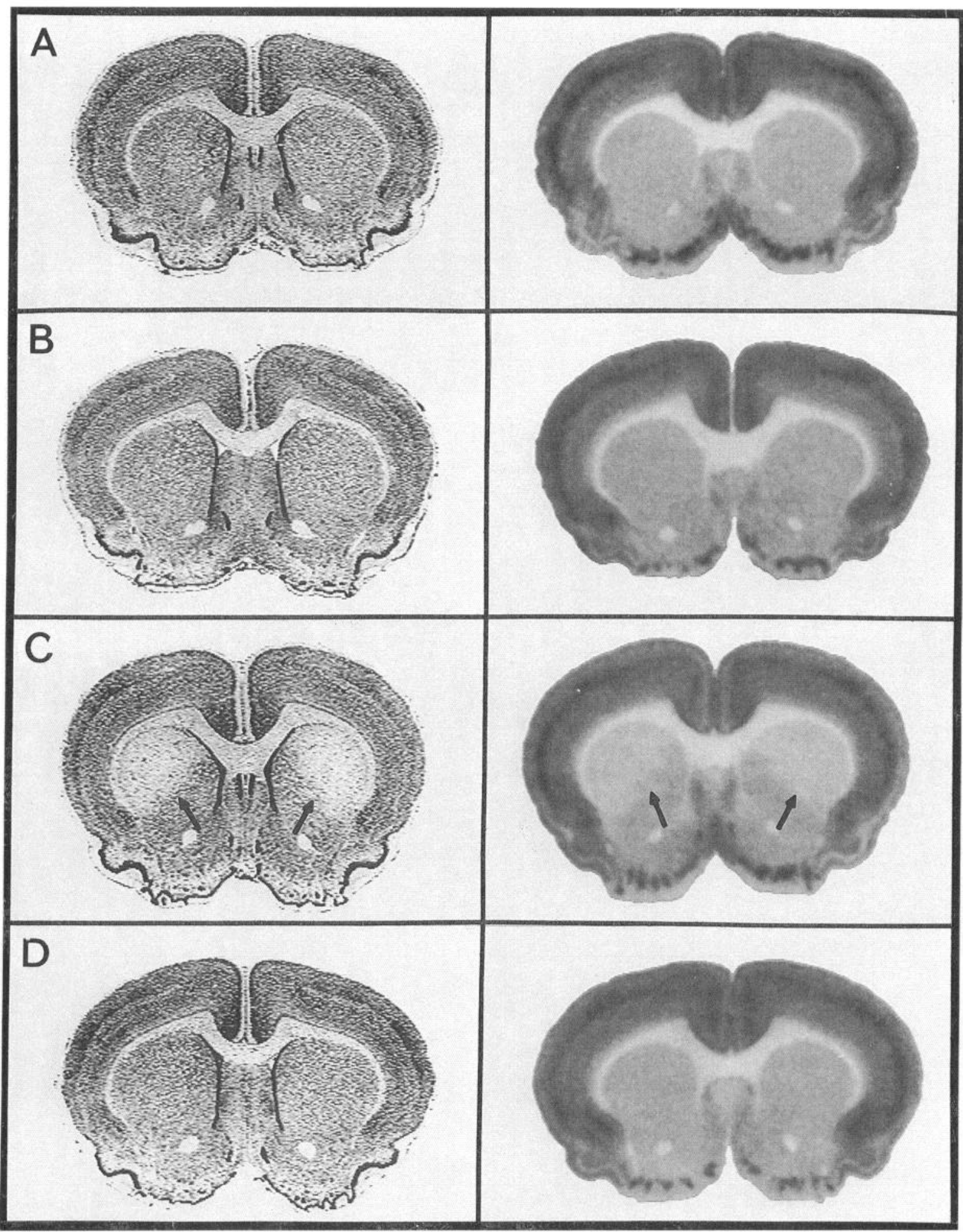

Figure 4. Representative sections from thionin stained striatum and from ${ }^{35} \mathrm{~S}-\mathrm{TBPS}$ autoradiograms show complete neuroprotection by diazepam. Rats were sacrificed $4 \mathrm{~d}$ following the onset of reperfusion. Adjacent striatal sections were stained with thionin for histological analysis and digitized (left) or subjected to ${ }^{35} \mathrm{~S}$-TBPS autoradiography to measure the density of $\mathrm{GABA}_{\mathrm{A}}$ receptors $($ right $)$. $A=\operatorname{sham}, B=\operatorname{sham}+$ diazepam, $C=$ ischemia, $D=$ ischemia + diazepam. Arrows point to area of damage and loss of binding. In the autoradiograms, the greatest density of ${ }^{35} \mathrm{~S}-\mathrm{TBPS}$ binding is indicated in black. 


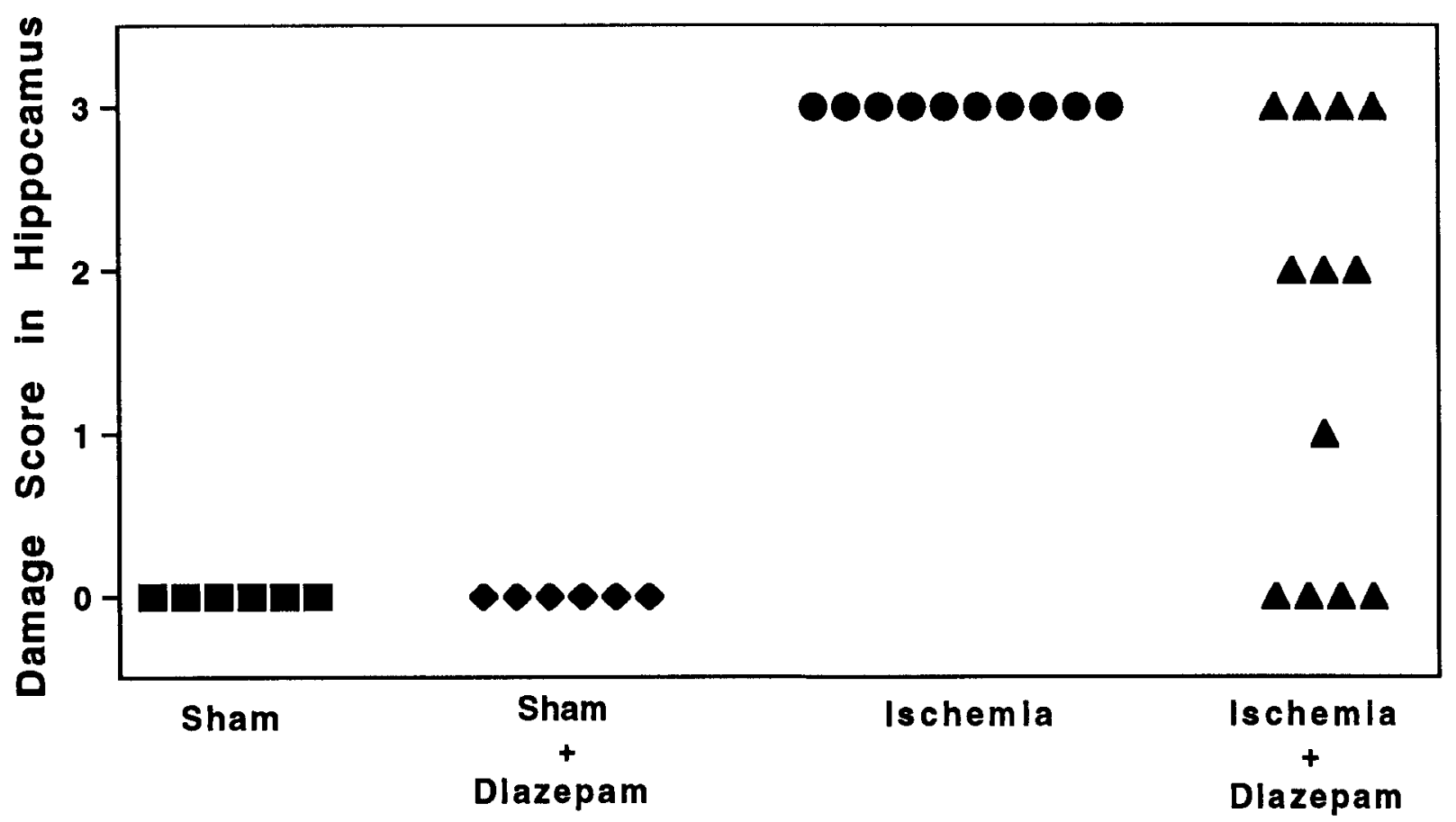

Figure 5. Diazepam protects hippocampal neurons and spares $\mathrm{GABA}_{\mathrm{A}}$ receptors in dendritic fields of CAl hippocampus following cerebral ischemia. Rats were sacrificed $4 \mathrm{~d}$ following transient global ischemia, and thionin-stained sections of hippocampus were examined for degeneration as described in Materials and Methods). Rats were administered diazepam $(10 \mathrm{mg} / \mathrm{kg}) 60$ and $120 \mathrm{~min}$ after cerebral ischemia. Each symbol represents an individual rat. Diazepam produced significant protection of pyramidal neurons in the CA1 area of the hippocampus. $p=0.002$, Kruskal-Wallis test followed by the Mann-Whitney $U$ test $(n=6,6,10$, and 12 , respectively).

to silver impregnation stain as described previously (Crain et al., 1988; Mileson and Schwartz, 1991). Degeneration of hippocampal pyramidal cells was measured semiquantitatively by comparing the digitized area of the CA1 pyramidal cell layer showing argyrophilic soma to the total area of the CA1 pyramidal cell layer (Crain et al., 1988; Mileson and Schwartz, 1991).

Autoradiography of ${ }^{35} S$-TBPS binding to $G A B A_{A}$ receptors. ${ }^{35} \mathrm{~S}-\mathrm{TBPS}$ binding to GABA-gated chloride channels was assessed in adjacent sections to those used for histology as we described previously (Edgar and Schwartz, 1990). Slide-mounted sections for autoradiography were dessicated overnight at $4^{\circ} \mathrm{C}$ and stored at $-70^{\circ} \mathrm{C}$. Sections were thawed and preincubated at room temperature in buffer containing $50 \mathrm{mM} \mathrm{K}_{2} \mathrm{HPO}_{4}$ / $\mathrm{NaH}_{2} \mathrm{PO}_{4}, 200 \mathrm{~mm} \mathrm{NaCl}, \mathrm{pH} 7.4$, and 1 mM EDTA to remove endogenous GABA. Sections were incubated for $3 \mathrm{hr}$ at room temperature in buffer described above (without EDTA) containing 1 to $2 \mathrm{nM}{ }^{35} \mathrm{~S}$-TBPS (New England Nuclear, Boston, MA; specific activity $50-100 \mathrm{Ci} / \mathrm{mmol}$ ). Following incubation, sections were washed two times for $15 \mathrm{~min}$ in buffer, dipped in distilled water, and dried under a stream of air. Nonspecific binding, determined in the presence of excess picrotoxin $(100$ $\mu \mathrm{M})$ in the incubation medium, was less than $5 \%$ of total binding and undetectable on film (Edgar and Schwartz, 1990). Sections were apposed to Hyperfilm-Betamax (Amersham, Arlington Heights IL) in x-ray cassettes for 2-3 d. Film was processed using Kodak D-19 developer and fixer. Autoradiographic images were digitized and quantitated using Image 1.49 software from NIH (Bethesda, MD) and with a MACQuadra 950. Optical densities were converted to fmol using a standard curve generated with plastic strips of ${ }^{14} \mathrm{C}$ standards calibrated to ${ }^{35} \mathrm{~S}$ standards prepared from brain-mash sections as described previously (Edgar and Schwartz, 1990; Miller, 1991).

Data analysis. Differences among group means were analyzed using the Krukal-Wallis test followed by the Mann-Whitney $U$ test for individual comparisons. Paired comparisons were made using the paired Student's $t$ test. A probability level of $<0.05$ was considered to be statistically significant.

\section{Results}

The first experiment was carried out to determine the best time to inject diazepam following transient cerebral ischemia. During cerebral ischemia, extracellular GABA levels become elevated substantially (Globus et al., 1988). When GABA levels are saturating, diazepam will not have an effect because it shifts the GABA dose-response curve to the left in a parallel manner (Tallman et al., 1980; Study and Barker, 1981). Therefore, we used in vivo microdialysis to monitor the extracellular levels of GABA during and after cerebral ischemia. Extracellular GABA was clcvatcd 4-50 timcs above the basal level in response to the ischemia and returned toward basal levels by $45-60 \mathrm{~min}$ following ischemia (Fig. 1). Based on these findings, we injected diazepam 60 min following ischemia in all subsequent experiments.

During transient global ischemia, normothermia was maintained (rectal temperatures ranged from $36.5-37.5^{\circ} \mathrm{C}$ ) (Fig. 2). Temporalis muscle temperature was maintained between 36.0 $37.0^{\circ} \mathrm{C}$ during ischemia. One hour following the onset of ischemia, rats were injected with a sedating dose of diazepam (10 $\mathrm{mg} / \mathrm{kg}$, i.p.). This dose of diazepam produced hypothermia; diazepam decreased rectal temperature by $1.5^{\circ} \mathrm{C}$ over the next hour (Fig. 2). A second injection of diazepam $2 \mathrm{hr}$ after ischemia decreased rectal temperature by an additional $1-1.5^{\circ} \mathrm{C}$ over the next $2 \mathrm{hr}$. The hypothermia reached a plateau at $33.5^{\circ} \mathrm{C}$ by 4 $\mathrm{hr}$ following the ischemia.

Four days following reperfusion, rats were sacrificed, and sections of striatum and hippocampus were examined for neuronal loss. Delayed administration of diazepam produced substantial protection of striatal neurons (Figs. 3, 4). Protection of striatal neurons was nearly complete to complete in $69 \%$ of the rats; little to no protection was observed in $31 \%$ of the rats. Complete protection of striatal sections stained with thionin from individual rats is shown in Figure 4. Diazepam also produced significant protection of pyramidal neurons in the CAl sector of 


\section{Thionin}

\section{${ }^{35}$ S-TBPS}

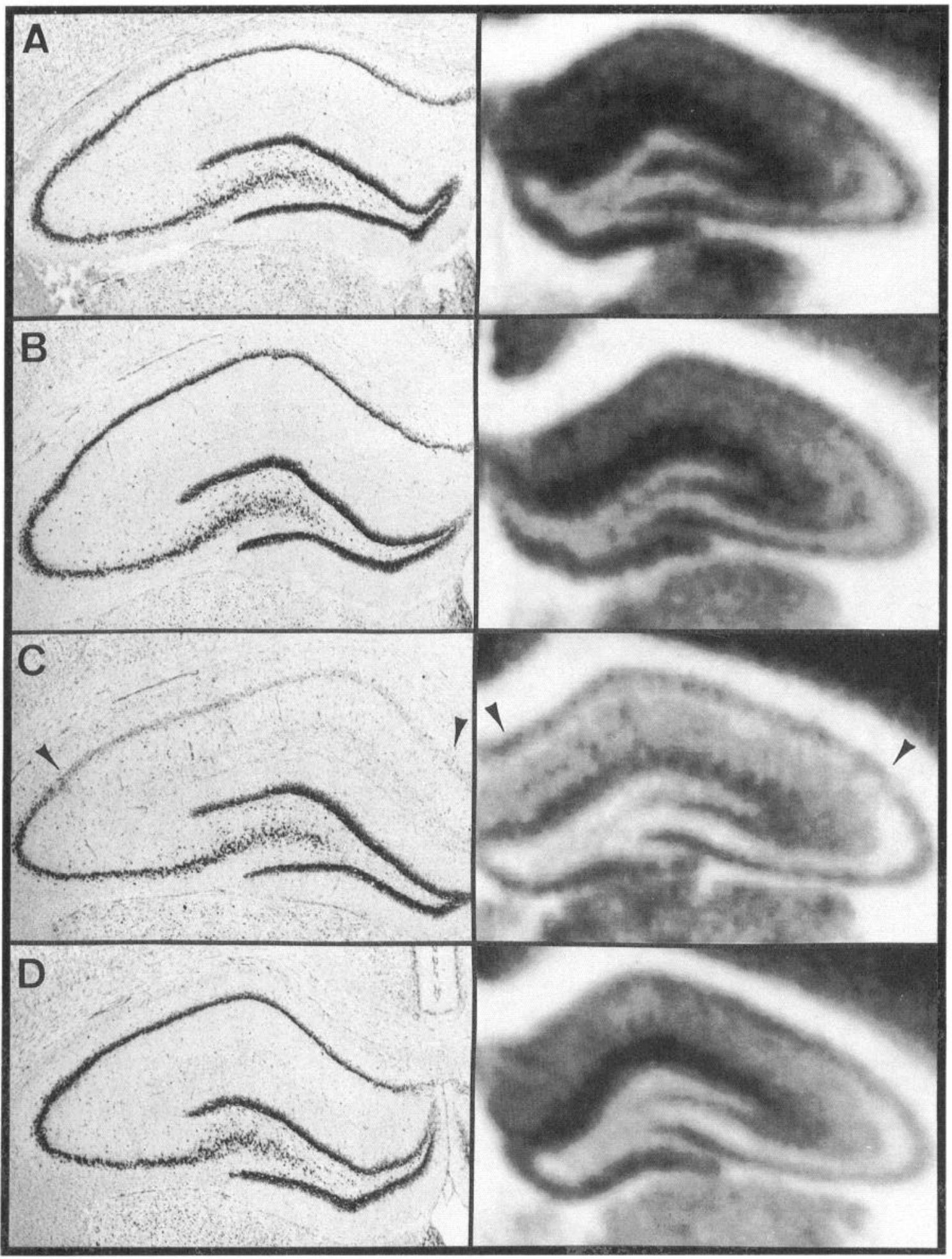

Figure 6. Representative sections from thionin-stained hippocampus and from ${ }^{35}$ S-TBPS autoradiograms show complete neuroprotection by diazepam. Rats were sacrificed $4 \mathrm{~d}$ following the onset of reperfusion. Adjacent sections at the level of the dorsal hippocampus were stained with thionin for histological analysis (left) or subjected to ${ }^{35} \mathrm{~S}$-TBPS autoradiography to measure the density of GABA $\mathrm{A}_{\mathrm{A}}$ receptors $($ right $)$. $A=$ sham, $B$ = sham + diazepam, $C=$ ischemia, $D=$ ischemia + diazepam. Black pointers indicate the CAl sector in which there is loss of pyramidal cell bodies and ${ }^{35} \mathrm{~S}$-TBPS binding in dendritic fields. 


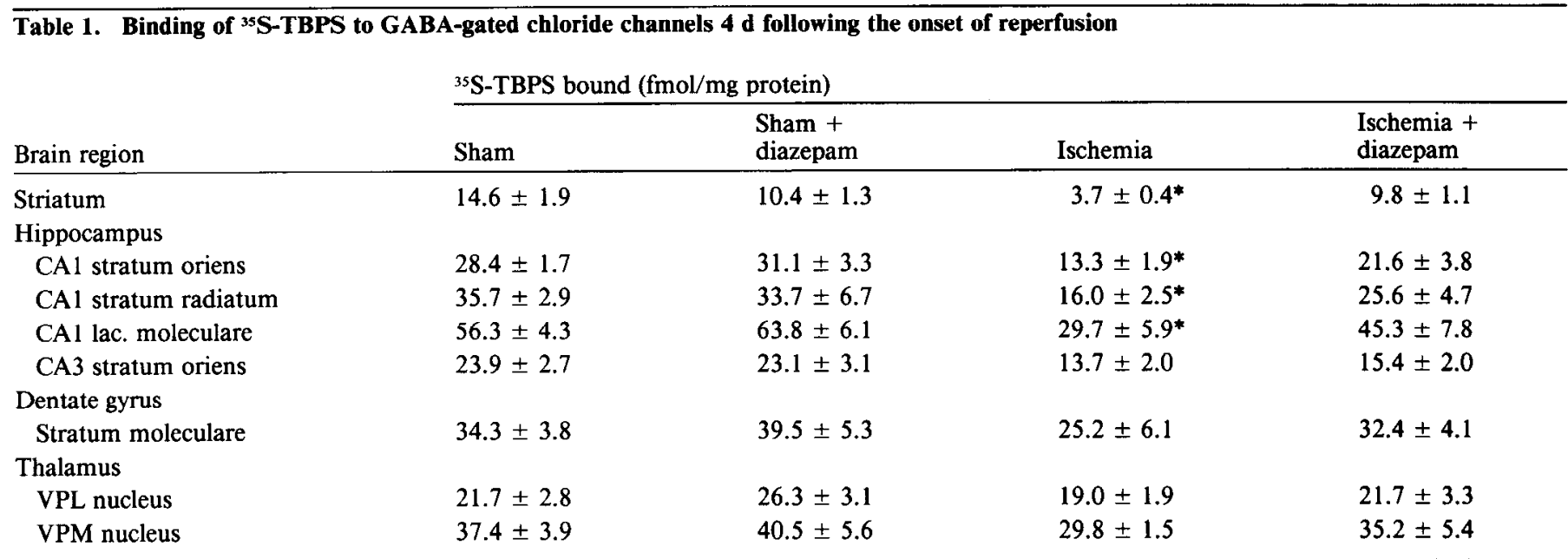

Brain sections adjacent to those used for histology were subjected to ${ }^{35} \mathrm{~S}$-TBPS autoradiography as described in Materials and Methods. Data are femtomoles of ${ }^{35} \mathrm{~S}-\mathrm{TBPS}$ bound/mg protein \pm the SEM of 5-7 rats. Abbreviations: VPL, ventroposterior lateral; VPM, ventroposterior medial.

$* p<0.05$, compared to sham; all other comparisons are not significantly different, Kruskal-Wallis test followed by the Mann-Whitney $U$ test.

the hippocampus (Figs. 5, 6). Protection was complete in 33\% of the rats. Partial protection was obtained in $33 \%$, and no protection was obtained in $33 \%$ of the rats. Complete protection of hippocampal sections from individual rats is shown in Figure 6.

Previously, we reported that $\mathrm{GABA}_{\mathrm{A}}$ receptors labeled with ${ }^{35} \mathrm{~S}$-TBPS were lost concomitantly with degeneration of striatal and hippocampal neurons following transient cerebral ischemia (Mileson et al., 1992). To determine if $\mathrm{GABA}_{\mathrm{A}}$ receptors were spared along with protected neurons, we measured the binding of ${ }^{35} \mathrm{~S}$-TBPS to GABA-gated chloride channels in brain sections adjacent to those used for histological analysis (Figs. 4 and 6 and Table 1). ${ }^{35} \mathrm{~S}$-TBPS binding was reduced significantly in the dorsolateral striatum and in the dendritic fields (strata oriens, radiatum, and lacunosum moleculare) of the CAl sector of the hippocampus (Table 1). ${ }^{35} \mathrm{~S}$-TBPS binding was not affected in areas of the thalamus that were also subjected to ischemia. Diazepam significantly prevented the loss of $\mathrm{GABA}_{\mathrm{A}}$ receptors in the dorsolateral striatum and in the dendritic fields of the hippocampus (Table 1). In brain sections from individual rats, the complete sparing of $\mathrm{GABA}_{\mathrm{A}}$ receptors by diazepam can be observed (Figs. 4, 6).

Hypothermia, produced by diazepam, is a common effect of many neuroprotective drugs. Hypothermia, induced physically, has also been shown to be neuroprotective in animals subjected to ccrcbral ischemia (Busto et al., 1987; Minamisawa et al., 1990; Welsh et al., 1990). To determine if the neuroprotective efficacy of diazepam was related to its ability to produce hy-

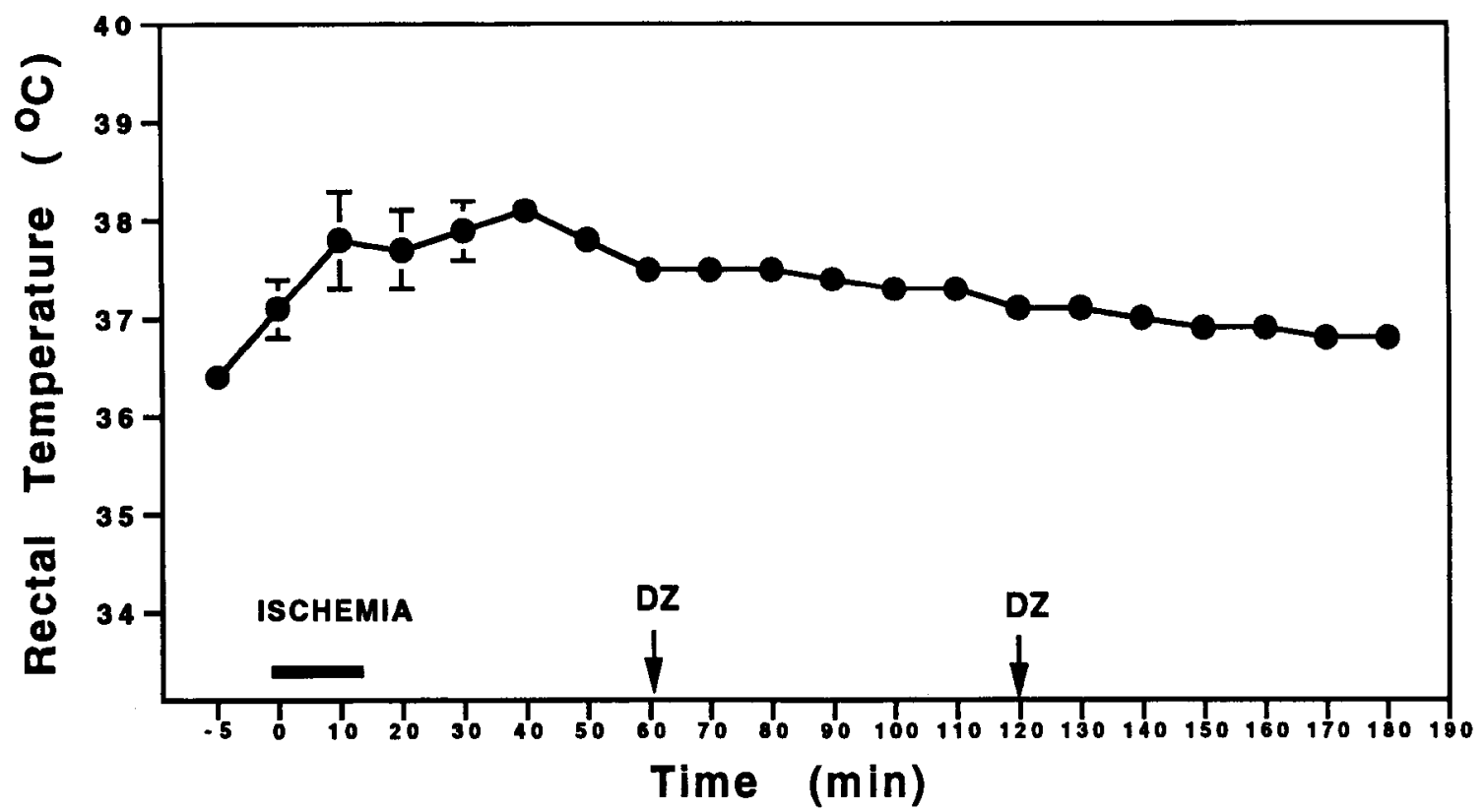

Figure 7. Diazepam, injected into the CAl hippocampus, fails to produce hypothermia. Sixty and 120 minutes following ischemia, rats were microinjected with vehicle into the CA1 sector of the hippocampus on one side of the brain and with diazepam (1.25 $\mu \mathrm{g})$ on the contralateral side. Rectal temperature was monitored before, during, and after drug injections. Rats remained normothermic throughout the experiment. Data are the mean \pm SEM of eight rats. Error bars are omitted when smaller than the symbol. 


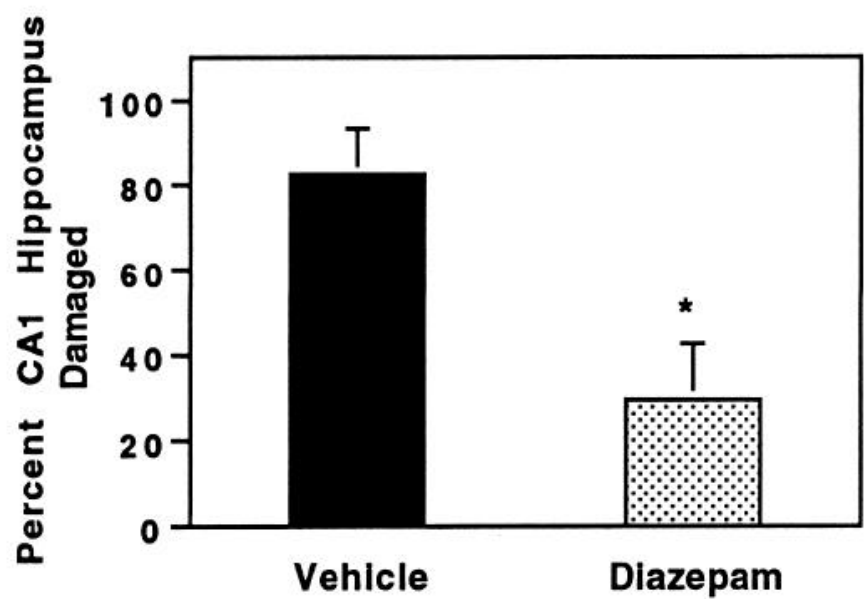

Figure 8. Diazepam, injected into the CA1 hippocampus after cerebral ischemia, is neuroprotective. Sixty and 120 minutes following ischemia, rats were microinjected with vehicle into the CAl sector of the hippocampus on one side of the brain and with diazepam $(1.25 \mu \mathrm{g})$ on the contralateral side. The extent of neuronal degeneration in the CA1 sector of the hippocampus was assessed as described in Materials and Methods. Data are the mean \pm SEM from six rats. Diazepam produced significant protection of pyramidal cells compared to the contralateral side ( $p=$ 0.002 , Student's paired $t$ test).

pothermia, we maintained normothermia (physically) after the injection of diazepam. However, the physical manipulation of core temperature was very stressful to the animal (unpublished observations) so we considered this to be an unacceptable experiment. Instead, we injected diazepam directly into the hippocampus, 60 and $120 \mathrm{~min}$ after the ischemia (the same dosing regimen used for systemic administration). When diazepam was administered directly into the hippocampus, no hypothermia was produced (Fig. 7). Four days after the onset of perfusion, the hippocampus on each side of the brain was examined for neuronal degeneration. Compared to the vehicle-injected side, diazepam produced substantial protection of pyramidal neurons in the CA1 sector on the contralateral side (Fig. 8). Complete neuroprotection of the entire hippocampus was achieved even in a severely ischemic rat (Fig. 9A,B). This was surprising, since it is almost impossible to achieve neuroprotection pharmacologically when the ischemic insult is severe (Buchan et al., 1991; Warner et al., 1991). Under higher magnification, individual degenerating CA1 pyramidal cells showing argyrophilia from a mildly ischemic rat were observed along with complete neuroprotection on the contralateral side injected with diazepam (Fig. 9C,D).

\section{Discussion}

We have shown that delayed administration of diazepam after cerebral ischemia prevents neuronal degeneration in vulnerable regions of the striatum and hippocampus. Postischemic hypothermia may have contributed to the neuroprotection by diazepam when it was administered systemically but the neuroprotective effect of diazepam did not require hypothermia (when administered into the hippocampus). Furthermore, a repeated dosing regimen was not required. The dosing regimen (two injections commencing $1 \mathrm{hr}$ after ischemia) produced excellent neuroprotective efficacy in the striatum $(69 \%$ of the rats were completely protected). The greater efficacy of diazepam (for a given dose) in the striatum compared to hippocampus is similar to the greater efficacy of both glutamate receptor antagonists and hypothermia to protect striatal neurons compared to hippocampal neurons (Warner et al., 1991). In the hippocampus, a greater degree of neuroprotection might have been achieved with a higher dose or with an additional dose of diazepam. However, we have found that this dose of diazepam (given 30 min after ischemia) produces neuroprotection to a greater degree in the gerbil hippocampus, compared to the rat (Schwartz et al., 1994a). The neuroprotective efficacy of diazepam was evident $4 \mathrm{~d}$ after the ischemic episode. Additional experiments will be required to determine if the neuroprotection is long lasting or whether damage is merely delayed. Interestingly, Lyden and Lonzo (1994) have found that the combination of a GABA agonist (muscimol) and an $N$-methyl-D-aspartate antagonist (MK-801) is neuroprotective in the rat cortex, when assessed 3 months after an embolic stroke.

The time after ischemia at which diazepam is administered may be critical (the "therapeutic window"). During and immediately following cerebral ischemia, GABA is released from neurons and accumulates in the extracellular space due to failure of energy-dependent reuptake pumps (Globus et al., 1988; Nakata et al., 1993). Benzodiazepines enhance GABA neurotransmission by shifting the GABA concentration-response curve to the left, thereby increasing GABA potency (Tallman et al., 1980; Study and Barker, 1981). Therefore, benzodiazepines should only be efficacious when extracellular GABA concentrations have declined back to basal levels, i.e., by $30-45 \mathrm{~min}$ following ischemia (see Fig. 1). This may explain why diazepam failed to protect hippocampal neurons when it was given $5 \mathrm{~min}$ after transient forebrain ischemia in the gerbil (Sternau et al., 1989). It is not known if diazepam administered 5 min after ischemia in the rat is neuroprotective. In another study, a much lower dose of diazepam, administered postischemia, did not protect hippocampal neurons, yet it did protect cerebral cortical neurons (Voll and Auer, 1991).

The neuroprotection achieved by diazepam injected directly into the hippocampus raises two important issues. First, the experiment shows that neuroprotection occurs in the absence of hypothermia. There is considerable evidence that hypothermia, present during an ischemic event, is neuroprotective (Busto et al., 1987; Welsh et al., 1990). However, hypothermia, induced after ischemia, during the first $2 \mathrm{hr}$ of reperfusion, is neuroprotective in some cases but not others (Busto et al., 1989; Welsh and Harris, 1991; Coimbra and Wieloch, 1994). Thus, while hypothermia is not required for neuroprotection by diazepam, still it may be involved in the protection achieved when diazepam is administered systemically. This is highly desirable, since hypothermia is induced routinely as a neuroprotective measure during cardiopulmonary bypass surgery and cardiac arrest, or after stroke and brain injury (Newburger et al., 1993). Second, the experiment demonstrates for the first time that enhancement of GABA neurotransmission within the area of vulnerability after an ischemic event is neuroprotective. This provides indirect evidence that GABA neurotransmission plays a role in the development of neuronal death following an ischemic insult. Direct evidence has been difficult to show, but several studies, when considered together, support this theory. First, the functional responses of $\mathrm{GABA}_{\mathrm{A}}$ receptors, in vitro, are attenuated by several mediators of ischemia-induced neuronal death. These include activation of phospholipase $\mathrm{A}_{2}$, generation of arachidonic acid and its metabolites, generation of superoxide radicals (Schwartz et al., 1988; Schwartz and Yu, 1992), and the influx 


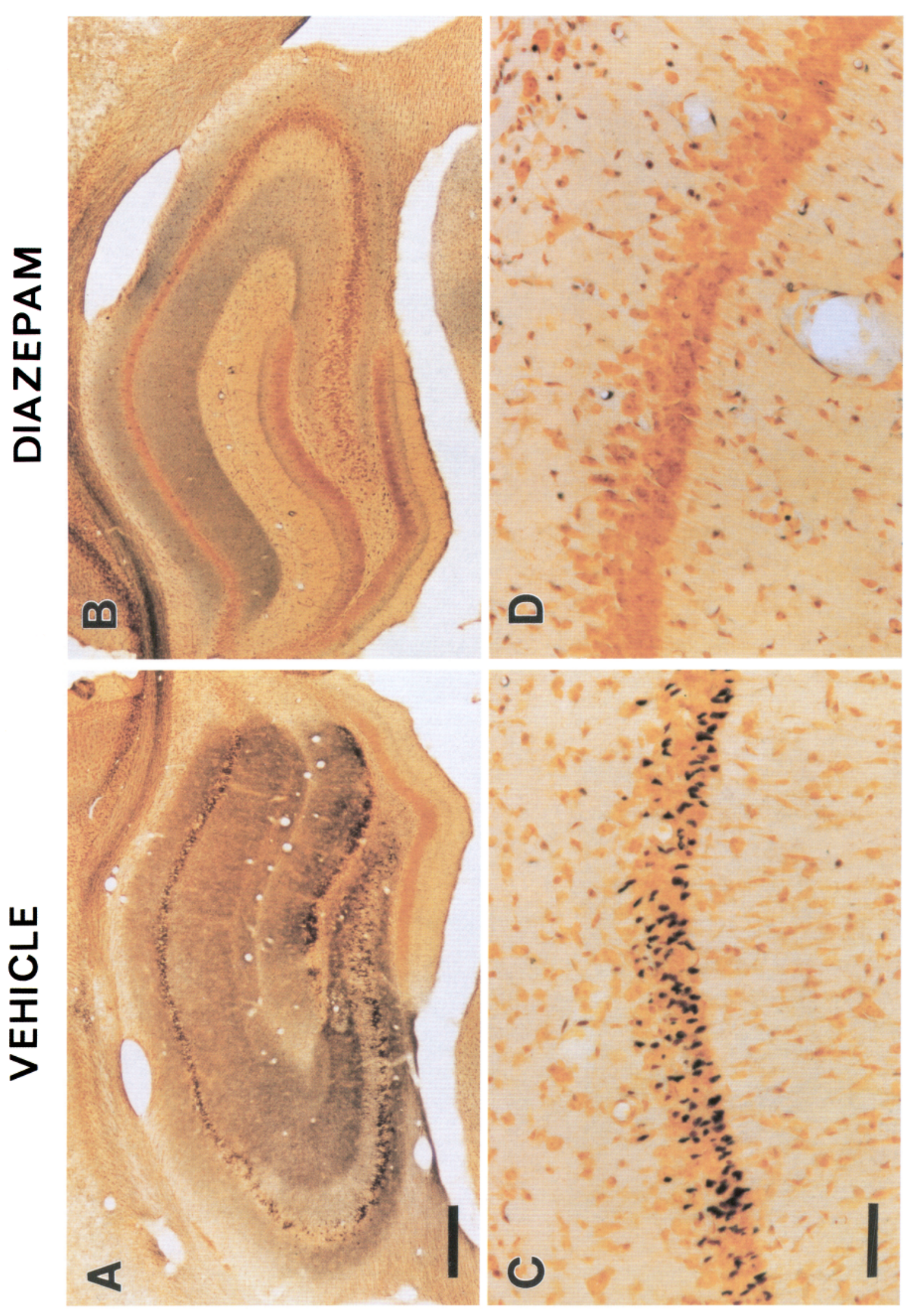

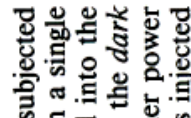

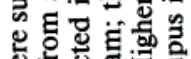

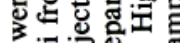

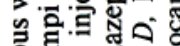

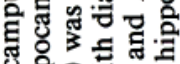
응

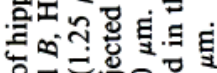

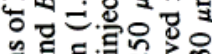
气ิ 政 ผ

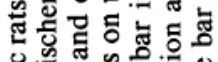

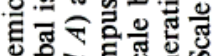

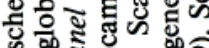

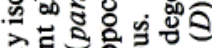

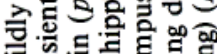

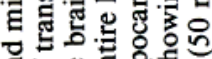

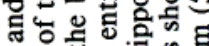

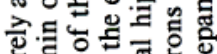

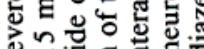

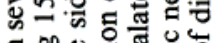

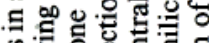
능웡 흉응

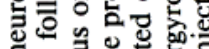

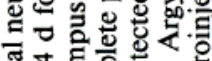

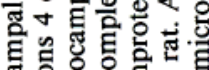
등 응연.

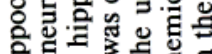

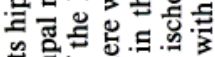

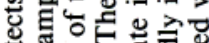

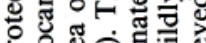

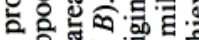

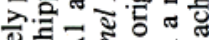
원현.

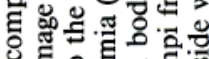
들

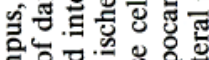

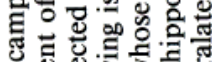

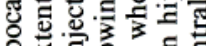
을 저음응 쁘유.

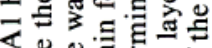
U。

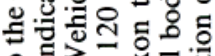
일 정

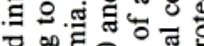

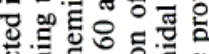

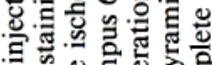

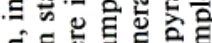

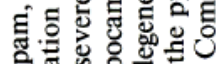
颉

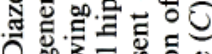

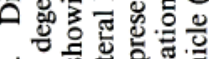
จ

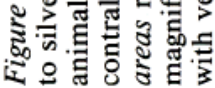


of calcium into neurons (Inoue et al., 1986; Schwartz et al., 1994b). Second, we have shown that there is a rapid decline (within hours) in $\mathrm{GABA}_{\mathrm{A}}$ receptor subunit mRNA levels in hippocampal neurons well before they die after an ischemic event ( $\mathrm{Li}$ et al., 1993). Third, GABA ${ }_{\mathrm{A}}$ responses decline in forebrain synaptoneurosomes from gerbils sacrificed within $2 \mathrm{hr}$ of the ischemic episode (Verheul et al., 1993). Fourth, increased neuronal excitability or a loss of synaptic inhibition (presumably mediated by GABA) can occur early in the reperfusion phase (Suzuki et al., 1983; Kawai et al., 1992). Thus, after cerebral ischemia, inhibitory neurotransmission may be attenuated, thereby contributing to or promoting neuronal death. The neuroprotective efficacy of GABA-enhancing agents at a critical time following an ischemic event supports this idea.

\section{References}

Benveniste H, Drejer J, Schousboe A, Diemer NH (1984) Elevation of the extracellular concentrations of glutamate and aspartate in rat hippocampus during transient cerebral ischemia monitored by intracerebral microdialysis. J Neurochem 43:1369-1374.

Buchan A, Ki H, Pulsinelli WA (1991) The $N$-methyl-D-aspartate antagonist, MK-801, fails to protect against neuronal damage caused by transient, severe forebrain ischemia in adult rats. $\mathrm{J}$ Neurosci 11: 1049-1056.

Busto R, Dietrich WD, Globus MY-T, Valdes T, Scheinberg P, Ginsberg MD (1987) Small differences in intraischaemic brain temperature critically determine the extent of ischaemic neuronal injury. J Cereb Blood Flow Metab 7:720-738.

Busto R, Dietrich WD, Globus MY-T, Ginsberg MD (1989) Postischemic moderate hypothermia inhibits CAl hippocampal ischemic neuronal injury. Neurosci Lett 101:299-304.

Choi DW (1988) Glutamate neurotoxicity and diseases of the nervous system. Neuron 1:623-634.

Coimbra C, Wieloch T (1994) Moderate hypothermia mitigates neuronal damage in the rat brain when initiated several hours following transient cerebral ischemia. Acta Neuropathol (Berl) 87:325-331.

Crain BJ, Westerkam WD, Harrison AH, Nadler JV (1988) Selective neuronal death after transient forebrain ischemia in the Mongolian gerbil: a silver impregnation study. Neuroscience 27:387-402.

Edgar PP, Schwartz RD (1990) Localization and characterization of ${ }^{35}$ S]t-butylbicyclophosphorothionate binding in rat brain: an autoradiographic study. I Neurosci 10:603-612.

Gill R, Foster A, Woodruff $G$ (1988) MK-801 is neuroprotective in gerbils when administered during the post-ischemic period. Neuroscience 25:847-855.

Globus MY-T, Busto R, Dietrich WD, Martinez E, Valdes I, Ginsberg MD (1988) Intraischemic extracellular release of dopamine and glutamate is associated with striatal vulnerability to ischemia. Neurosci Lett 91:36-40.

Inoue M, Oomura Y, Yakushiji T, Akaike N (1986) Intracellular calcium ions decrease the affinity of the GABA receptor. Nature 324 : 156-158.

Ito U, Spatz M, Walker T, Klatzo I (1975) Experimental cerebral ischemia in Mongolian gerbils I. Light microscopic observations. Acta Neuropathol (Berl) 32:209-223.

Johansen FF, Diemer NH (1991) Enhancement of GABA neurotransmission after cerebral ischemia in the rat reduces loss of hippocampal CAl pyramidal cells. Acta Neurol Scand 84:1-6.

Kato H, Araki T, Kogure K (1990) Role of the excitotoxic mechanism in the development of neuronal damage following repeated brief cerebral ischemia in the gerbil: protective effects of MK-801 and pentobarbital. Brain Res 516:175-179.

Kawai K, Penix LP, Tuetzler CA, Nitecha L, Lohr JM, Klatzo I (1992) Effect of cardiac arrest cerebral ischemia on the GABAergic system and development of audiogenic seizures. In: Pharmacology of cerebral ischemia (Krieglstein J, Oberpichler-Schwenk H, eds), pp 195-206. Stuttgart: Wissenschaftliche.

Kirino $T$ (1982) Delayed neuronal death in the gerbil hippocampus following ischemia. Brain Res 239:57-69.

Krieglstein J (1990) Pharmacology and drug therapy of cerebral ischemia. In: Cerebral ischemia and resuscitation (Schurr A, Rigor BM, eds), pp 347-371. Boca Raton: CRC.
Levy DE, Brierley JB (1979) Delayed pentobarbital administration limits ischemic brain damage in gerbils. Ann Neurol 5:59-64.

Levy DE, Caronna JJ, Singer BH, Lipinski RH, Frydman H, Plum F (1985) Predicting outcome from hypoxic-ischemic coma. JAMA 253: $1420-1426$

Li H, Buchan AM (1993) Treatment with an AMPA antagonist 12 hours following severe normothermic forebrain ischemia prevents CA1 neuronal injury. J Cereb Blood Flow Metab 13:933-939.

Li H, Siegel RE, Schwartz RD (1993) Rapid decline of GABA receptor subunit mRNA expression in hippocampus following transient cerebral ischemia in the gerbil. Hippocampus 3:527-538.

Lyden PD, Lonzo L (1994) Combination therapy protects ischemic brain in rats. Stroke 25:189-196.

Mileson BE, Schwartz RD (1991) The use of locomotor activity as a behavioral screen for neuronal damage following transient forebrain ischemia in gerbils. Neurosci Lett 128:71-76.

Mileson BE, Ehrmann ML, Schwartz RD (1992) Alterations in the GABA-gated chloride channel following transient forebrain ischemia in the gerbil. $J$ Neurochem 58:600-607.

Miller JA (1991) The calibration of ${ }^{35} \mathrm{~S}$ or ${ }^{32} \mathrm{P}$ with ${ }^{14} \mathrm{C}$-labeled brain paste or ${ }^{14} \mathrm{C}$-plastic standards for quantitative autoradiography using LKB Ultrofilm or Amersham Hyperfilm. Neurosci Lett 121:211-214.

Minamisawa H, Nordström C-H, Smith M-L, Siesjö BK (1990) The influence of mild body and brain hypothermia on ischemic brain damage. J Cereb Blood Flow Metab 10:365-374.

Nakata N, Kato H, Kogure K (1993) Effects of repeated cerebral ischemia on extracellular amino acid concentrations measured with intracerebral microdialysis in the gerbil hippocampus. Stroke 24:458464.

Nellgard B, Wieloch T (1992) Post-ischemic blockade of AMPA but not NMDA receptors mitigates neuronal damage in the rat brain following transient severe cerehral ischemia. J Cereb Blood Flow Metab 12:2-11.

Newburger JW, Jonas RA, Wernovsky G, Wypij D, Kickey PR, Kuban KCK, Farrell DM, Holmes GL, Helmers SL, Constantinou J, Carrazana E, Barlow JK, Walsh AZ, Lucius KC, Share JC, Wessel DL, Hanley FL, Mayer JE Jr, Castandeda AR, Ware JH (1993) A comparison of the perioperative neurologic effects of hypothermic circulatory arrest versus low-flow cardiopulmonary bypass in infant heart surgery. N Engl J Med 329:1057-1064.

Petito CK, Feldmann E, Pulsinelli WA, Plum FA (1987) Delayed hippocampal damage in humans following cardiorespiratory arrest. Neurology 37:1281-1286.

Pulsinelli WA, Brierley JB, Plum F (1982) Temporal profile of neuronal damage in a model of transient forebrain ischemia. Ann Neurol $11: 491-498$.

Rall TW (1990) Hypnotics and sedatives; ethanol. In: Pharmacological basis of therapeutics (Gilman AG, Rall TW, Nies AS, Taylor P, eds), pp 345-382. New York: Pergamon.

Rothman SM (1984) Synaptic release of excitatory amino acid neurotransmitter mediates anoxic neuronal death. J Neurosci 4:18841891.

Schurr A, Rigor BM (1992) The mechanism of cerebral hypoxic-ischemic damage. Hippocampus 2:221-228.

Schwartz RD, Edgar PP (1990) Localization and characterization of $\left[{ }^{35}\right.$ S]t-butylbicyclophosphorothionate binding in rat brain: an autoradiographic study. J Neurosci 10:603-612.

Schwartz RD, Yu X (1992) Inhibition of GABA-gated chloride channel function by arachidonic acid. Brain Res 585:405-410.

Schwartz RD, Skolnick P, Paul SM (1988) Regulation of $\gamma$-aminobutyric acid/barbiturate receptor-gated chloride ion flux in brain vesicles by phospholipase $\mathrm{A}_{2}$ : possible role of oxygen radicals. J Neurochem 50:565-571.

Schwartz RD, Huff RA, Yu X, Carter M, Bishop M (1994a) Postischemic diazepam is neuroprotective in the gerbil hippocampus. Brain Res 647:153-160.

Schwartz RD, Wagner JP, Yu X, Martin D (1994b) Bidirectional modulation of GABA-gated chloride channels by divalent cations: Inhibition by $\mathrm{Ca}^{2+}$ and enhancement by $\mathrm{Mg}^{2+}$. J Neurochem 62:916922.

Shuaib A, Ijaz S, Hasan S, Kalra J (1992) Gamma-vinyl GABA prevents hippocampal and substantia nigra reticulata damage in repetitive transient forebrain ischemia. Brain Res 590:13-17.

Shuaib A, Mazagri R, Ijaz. S (1993) GABA agonist "muscimol" is neuroprotective in repetitive transient forebrain ischemia in gerbils. Exp Neurol 123:284-288. 
Simon R, Swan J, Griffith T, Meldrum B (1984) Blockade of $N$ methyl-D-aspartate receptors may protect against ischemic damage in the brain. Science 247:571-574.

Sternau LL, Lust WD, Ricci AJ, Ratcheson R (1989) Role for $\gamma$-aminobutyric acid in selective vulnerability in gerbils. Stroke 20:281287.

Study RE, Barker JL (1981) Diazepam and (-) pentobarbital: fluctuation analysis reveals different mechanisms for potentiation of GABA responses in cultered central neurons. Proc Natl Acad Sci USA 78: $7180-7184$

Suzuki R, Yamaguchi T, Choh-Luh L, Klatzo I (1983) The effects of 5-minute ischemia in Mongolian gerbils: II. Changes of spontaneous neuronal activity in cerebral cortex and CA1 sector of hippocampus. Acta Neuropathol (Berl) 60:217-222.

Tallman JF, Paul SM, Skolnick P, Gallager DW (1980) Receptors for the age of anxiety: pharmacology of benzodiazepines. Science 207: 274-281.

Verheul HB, de Leeuw F-E, Scholten G, Tulleken CAF, Lopes da Silva

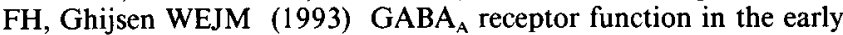
period after transient forebrain ischaemia in the rat. Eur J Neurosci $5: 955-960$.
Voll CK, Auer RN (1991) Post ischemic seizures and necrotizing ischemic brain damage: neuroprotective effect of postischemic diazepam and insulin. Neurology 41:423-428.

Volpe BT, Petito CK (1985) Dementia with bilateral medial temporal lobe ischemia. Neurology 35:1793-1797.

Warner MA, Neill KH, Nadler JV, Crain BJ (1991) Regionally selective effects of NMDA receptor antagonists against ischemic brain damage in the gerbil. J Cereb Blood Flow Metab 11:600-610.

Welsh FA, Harris VA (1991) Postischemia hypothermia fails to reduce ischemic injury in gerbil hippocampus. J Cereb Blood Flow Metab 11:617-620.

Welsh FA, Sims RE, Harris VA (1990) Mild hypothermia prevents ischemic injury in gerbil hippocampus. J Cereb Blood Flow Metab 10:557-563.

Yu X, Li H, Schwartz RD (1993) Diazepam is neuroprotective and preserves $\mathrm{GABA}_{\mathrm{A}}$ receptors in striatum but not in cerebral cortex following transient global ischemia in the rat. Soc Neurosci Abstr 19: 1648 . 